\section{Golf Without a Caddy}

By Elmer A. Sperry

COLFERS are being made faster than $G$ caddies. Nature apparently has litthe to do with the former, while we are compelled to leave it very much in control of the latter. It is more and more difficult to get caddies and those who do get them find them of little account. Some seasoned golfers absolutely refuse to carry their own bag over the course. No matter how experienced they may be they the is a decidedly startling and nd quite unsuspected reason why caddiless golf is exhausting. An analysis of the underlying causes is of more than ordinary interest. Everyone knows that he gets tired in toting his own golf bag, much more so than seems at all reasonable. An abundant reason for this fatigue is revealed, however, in the dynamics of the proposition, which involves elements heretofore neglected. Analysis reveals the fact that it isn't toting the bag that makes one tired ; in fact, we are quite familiar with the energies that this factor involves. It probably requires, in the great economics of nature, about 30 watt hours per tonmile to cover this part of the work. This means, where a player averages $21 / 2$ miles an hour, $21 /$ times 30 , or 75 watt-hours to be multiplied by the tonnage of the to be multiplied by the tonnage of the equals $100 / 266$ or for two hours a total of 200/266 wat hours, which, being interpreted, means about the power required to raise about one ton through the distance of one foot or about one foot-ton of energy. This may seem staggering, but it is quite an unimportant factor as compared with one other of much greater magnitude, and it is this latter which really saps the energy of the player, namely, picking up his bag and its constant repetition. This tires him far more than has stant repetition. This tires him far more than has been supposed

In lifting, it isn't the bag that weighs, but the man. We have lost sight of the player's own weight which is involved in this process. Suppose the player's cente of gravity is lowered 2 feet at each pick-up and raised again, and his weight is $\mathbf{1 5 0}$ pounds. He thus exerts 300 foot-pounds of energy in lifting his own weight regardless of any other factor. Again the muscular energy involved tor. Again the muscular energy involved
in lowering himself is understood very well and is about $1 / 1$ of the above amount, or 75 foot-pounds. Again another quantity occurs in the small amount of stooping and rising again in the act of lowering the bag to the ground before making his shot. No player drops his bag any great distance-the clubs are too valuable for this. This factor averages about 85 for this. This factor averages about 85 bag itself, say 10 pounds, through three bag itself, say 10 pounds, through three
feet, giving 30 foot-pounds additional for this item. Let us now add these items and see what it amount to- 300 plus 75 plus 85 plus 30 equals 490 foot-pounds. Now let us suppose the course is an average hard course and our average player requires 100 strokes to go around; he will use up no less than 49,000 foot-pounds will use up no less than 49,000 foot-pound foot-tons-more if he is a tall man, again more if he weighs in excess of 150 pounds, and doubly more if he is both, as many men are. And this in only one round. No wonder the player feels himself "all in" in toting his own bag in the old way. Here is an enormous store of energy that should be conserved for the game itself instead of being utterly and uselessly wastedand what a waste! The kind that causes exasperating delays upsetting one's own game, and what is most exasperating, often that of many others as well.

Practically all of these 24-odd foot-tons of energy per man per round can easily be saved by the simple expedient of an upstanding or stabilized bag. Put a spike in the bottom of your bag and drive it into the turf. Do anything rather than drop your sticks. Personally, I was appalled at the results of these simple calculations. Accurate information as to the

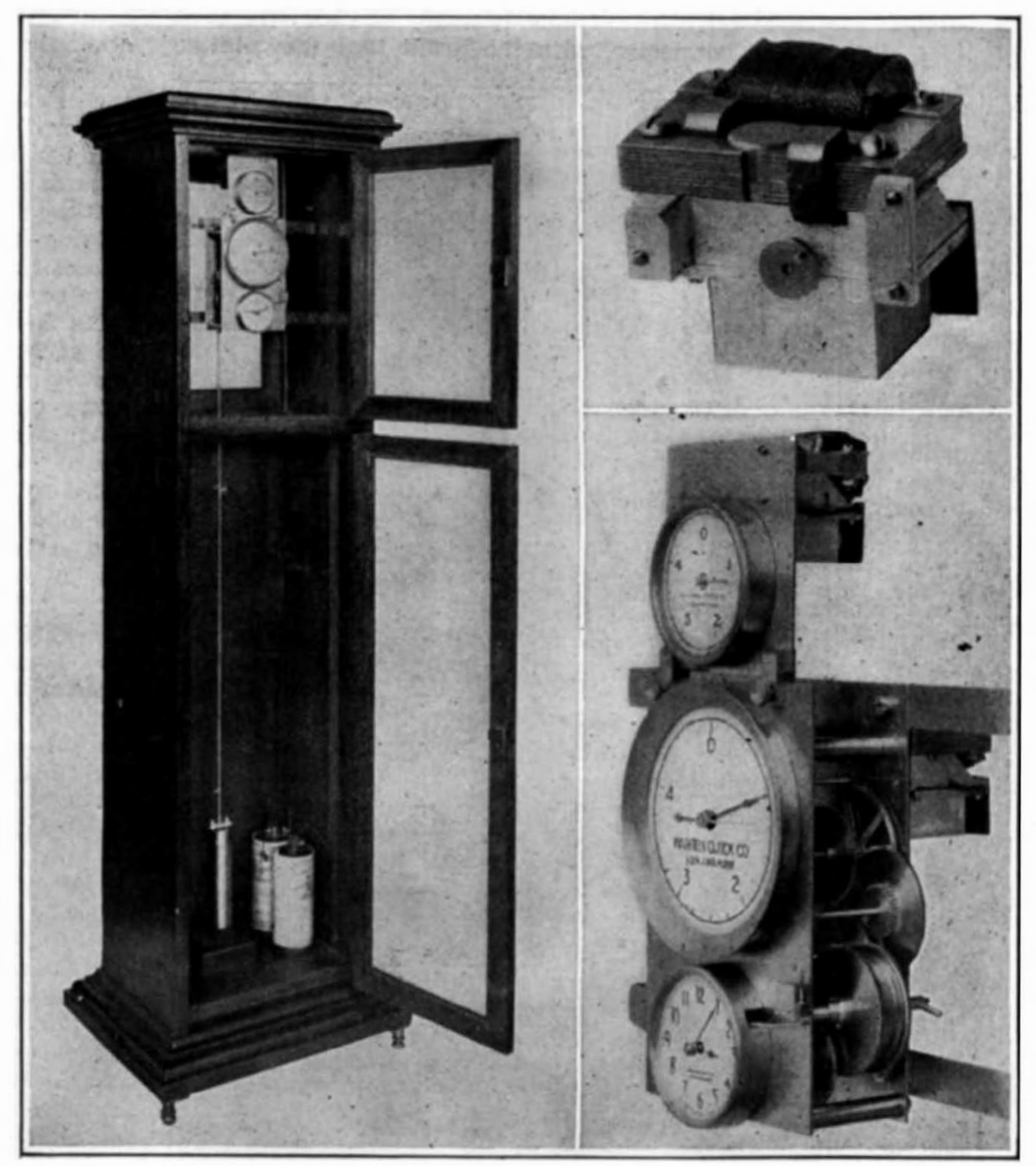

Left: Front view of the master clock. Upper right: The motor for the master clock. Lower right: Movement of the master clock

The motor-controlled synchronizing clock

\section{Keeping in Step}

By Ralph Howard

THE latest departure in synchronous 1 motor application is the installation of a very small self-starting motor in a clock, where it is used, in connection with a high grade clock movement, to compare the speed of a synchronous generator with exact time, in order to give a continuous check on generator frequency. Since any change in the speed of the generator is reflected in the speed of this small motor, whereas the clock speed remains constant, the combination forms an accurate method of maintaining constant average freof maint

These small motors can also be used on the system in place of clock mechanisms to drive graphic recording instruments, demand meters and time switches. By the use of this motor the synchronization of records from graphic meters and demand meters will be made possible; something that was always been desle bomething that has always been desirament heretofore.

In practice, a master clock containing two movements, one electrical, and one pendulum-operated, is located near the switchboard. The face is equipped with two pointers, one black, the other gold, rotating independently about the same center, on a dial, called the operating center, on a dial, called the operating
dial. The black pointer is so geared to real seat of a difficulty allows us to engineer around it, in fact, in this case to avoid it entirely. In my own case it is very gratifying to know the real reason for "that tired feeling" after caddiless golf and to find it not wholly due to advancing years after all. I am from the extra fatigue, finishing a round fresh and ready for more, by employing this simple device of the ustanding, stable bag.

In my case I have been able to accomplish this by a little attachment which I designed for my light "Sunday" bag. It weighs only a few ounces and can be readily attached or detached. This was made by my boys at the works, who seem to take extra pride in providing the boss with an energy-saving device. This (Continued on page 482) the pendulum clock as to make one complete revolution every five minutes. The gold pointer is geared to the small synchronous motor, so that when the fre quency is correct it will rotate at the same speed as the black hand. All that the operator has to do is to hold the two pointers together-he will then have a fixed relation maintained between standard time, and generator speed, or cycles and time. This can be done by adjusting the speed governors of the prime movers. The master clock does not obviate the use of a frequency meter, or indicator, since it will not show instantaneous fluctuations in speed. Moreover, by using a frequency indicator near the master clock, the latter may be used as a constant check on the accuracy f the former.

The little synchronous motor which is the vital part of the electric component of the clock is only $21 / 8$ by $25 \% 8$ by $29 / 16$ inches in size, and is wound for operation on a 110-volt circuit. It consumes less than 4 watts at 110 volts, 60 cycles, than 4 watts at 110 volts, 60 cycles, standard commercial frequencies. It is self-starting under load, reaches synchronous speed in less than a second and holds speed as long as the current is uninterrupted. It is simple in construction, and since its gearing runs permanently immersed in oil it requires but little attention to keep it functioning properly for an indefinite period.

There have been developed two forms of master clock, known as the type "A" and type "B." The principal difference in operation of these two is that in the "B" type, both the motor and the clock mechanism act on the same index hand, through gearing, so that the synchronous motor tends to drive the hand in one direction, while the clock mechanism tends to drive it in the opposite direction.

If the rate of the clock and motor are the same the hand rests at zero on the scale, but if the speed of the motor varies the hand is moved slowly in a clockwise or counter clockwise direction according to whether the variation is a gain or loss in speed. In this way the clock is caused to indicate variations in average frequency. The " $A$ " type is that first de scribed, in which control of the two speeds comes from comparison of two hands.

The installation of these master clocks will not eliminate fluctuations which are dependent to some degree on load variations, speed governor response, or steam pressure - features of operation which are more or less constantly encountered; but it does insure the maintenance of a more uniform as well as correct average frequency. 
4.

THE SHOE THAT HOLDS ITS SHAPE

\$7.00 \$8.00 \$9.00 \& \$10.00 SHOES FOR MEN AND WOMEN

YOU GAN SAVE MONEY BY WEARING W. L. DOUGLAS SHOES

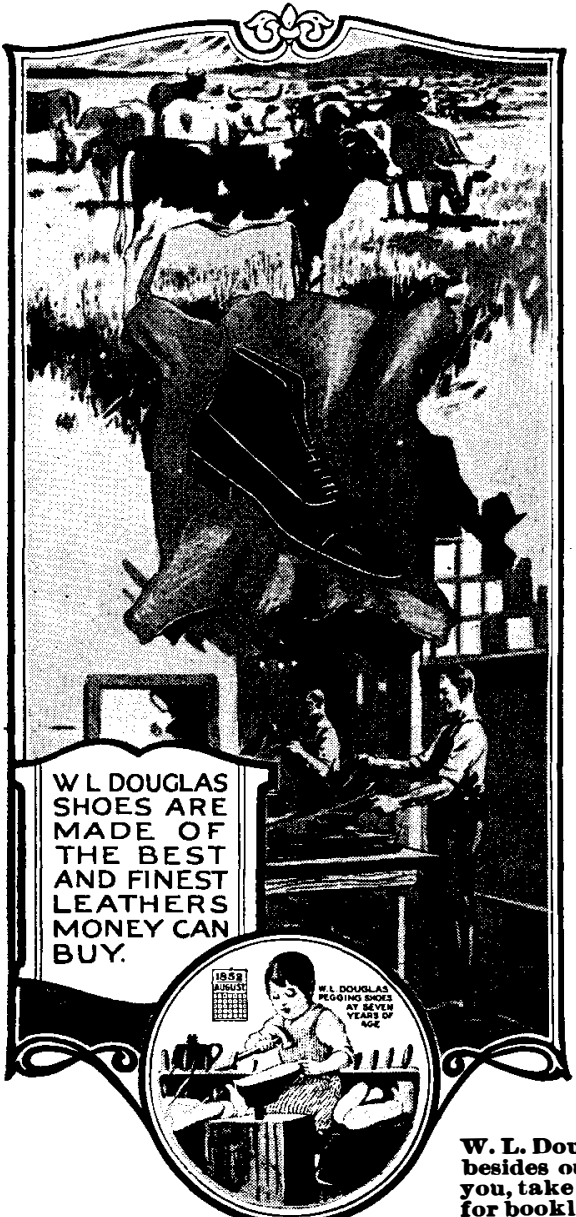

hebest known
shoes in the world. They are sold in $107 \mathrm{~W}$.L.

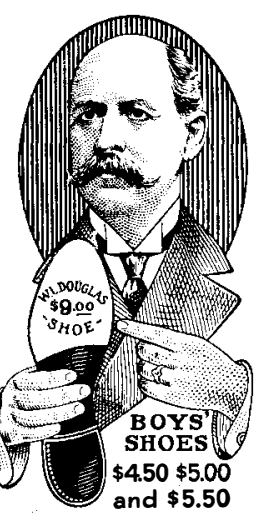
direct from the factory to you at only one profit, which guarantees to you the best shoes that can be produced, at the lowest possible the retail price are stamped on the bottom of all shoes before they leave the factory, which is your protection against unreasonable profits.

W. L. Douglas $\$ 9.00$ and $\$ 10.00$ shoes are absolutely the best shoe values for the money in this country. They are made of the best and finest leathers that money can buy. They combine quality, style, workmanship and wearing qualities equa to other makes selling at higher prices.
They are the leaders in the fashion centers of America. The stamped price is W. $L$. Douglas personal guarantee that the shoes
are always worth the price paid for them. The prices are the same everywhere; they cost no more in San Francisco than they do in New York.

W. L. Douglas shoes are made by the highest paid, skilled shoemakers, under the direction and supervision of experi-
enced men, all working with an honest determination to make the best shoes for the price that money can buy.

Wesidesugh own stores. If your lockil dealer cannot suppis

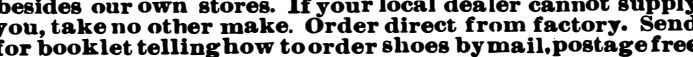

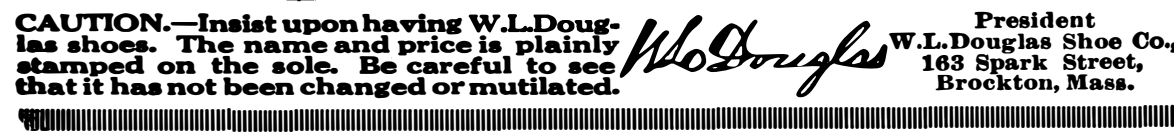

Whatever Your Question; -be it the pronunciation of Bolsheviki, the spelling of a puzzling word, the location of
Murman Coast-the meaning of blighty, etc.,this SupremeAuthority WEBSTER'S NEW INTERNATIONAL DICTIONARY

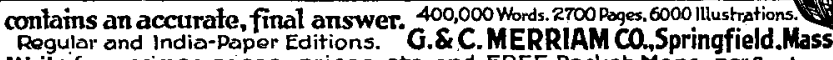

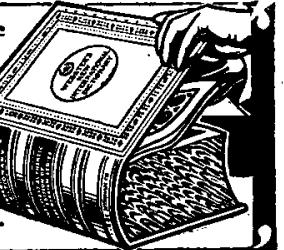

\section{R E L A T I V I T Y}

\section{The Special and the General Theory}

By Professor Albert Einstein, Ph.D. LL.D.

Translated by Professor Robert W. Lawson, M.Sc.

$T$

$\mathrm{HE}$ authorized English translation of Einstein's own book explaining his theories to the general public is now available. Dr. Einstein has scored a conspicuous success in this volume, steering a skillful course between the twin dangers of too much mathematics and too little explanation. Also, he makes clearer than has yet been made just wherein lies the dividing line between his special theory and his general theory, and just where the two join. In literary style as weIl as in clarity of exposition this book bids fair to take rank as a classic; and in any event, it is by far the most satisfactory treatment of the subject to be had at the presen date in English.

Price $\$ 2.50$, by Mail $\$ 2.58$

For Sale by

SCIENTIFIC AMERICAN PUBLISHING CO. 233 Broadway stalled and these loaded directly upon' Japanese boats of the Akikaze class, dump cars which were hauled away by building under the estimates for the curelectric locomotives, trains being made up rent year. They will displace 1,900 tons of five or six cars. Except where water and have a speed of 38 knots. Four, or was encountered in large volume, some possibly five, 5.5-inch 82-pounder rapidof the tunnel crews made as high as 12 fire guns will be mounted on the centerline, feet a day, and the work of drilling and and all six torpedo tubes can be trained mucking went on simultaneously. A on either beam. A feature of these boats heading, approximately 8 feet high and on either beam. A feature of these boats the full width of the tunnel, was carried is their large fuel capacity, which is exthe full width of the tumnet, was carried approximately 7 feet ahead or the bench. As soon as the shooting from a preceding shift had been completed, the steam shovel men immediately commenced to load out the muck which had been blown back from the face. The machine men and chuck tenders at the same time start work on the top of the muck and shove top of the bench. By carrying a short bench, it is possible to clear the same bench, it is possible to clear the same
with a minimum amount of hand muckwith a minimum amount of hand muck-
ing, thus enabling the drilling in the face to proceed at the same time that the steam shovel is mucking out the heading. This makes it possible for the tunnel work to proceed through the entire 24 hours of a day.

At one of the tunnels a different method of work was adopted. Here the crews were divided into drilling and mucking gangs, and worked separately. A car was specially built upon which was mounted a column 17 feet high with a jack on each end, with 4 cross bars mounted on the same, the drills being mounted on the cross bars. By this method the entire face of the tunnel was drilled and shot before the steam shove
started to work, and each crew worked in started to work, and each crew worked in
shifts. By this method a maximum speed of 90 feet in one week was obtained. Considerable rivalry existed between the various crews, and as the progress malle by each crew was posted, the men working in the different tunnels endeavored to outdo each other with the result that excellent pros

The penstock lines are of riveted steel pipe, 7 feet in diameter at the lower end and 8 feet in diameter at the upper end, at which point they are concreted into the mouth of the tunnel. A forebay 17 feet in diameter at the top, 80 feet in height and 40 feet in diameter at the top of the tunnel, has been excavated in solid rock a short distance from the outlet of the tunnel, where the penstock joins the same. The purpose of the forebay, from which a spillway leads to the river, is to take care of surges due to sudden in

he plant.

From the power house a 110,000 -volt transmission line about 75 miles in length carries the current to a point near Tulare Lake, where it is delivered to the distributing system for use where needed. Since the hydroelectric lines of all Cali-
fornia companies have been connected up fornia companies have been connected up
for emergency use, it is possible to send power generated at one point to any part of the State for use.

The "Super-Destroyer"

(Continued from page 472)

the guns, including director aiming and firing mechanism. It is, however, doubtful whether all this cumbersome and intricate gear was suitable for vessels which were simply enlarged destroyers, and therefore exposed to the sort of rough and tumble fighting in which headlong dash counts for more than science. Moreover, 5.9-inch gun, with its 101-pound projectile, is much too heavy to be conveniently manhandled on the slippery decks of a boat which is moving all ways at once. In theory, the German "V-116" leaders ought to have made short work of any destroyers they were likely to meet in the North Sea in practice they would probably have been beaten by the smaller British boats armed with the handy 4-inch and 4.7-inch gun. A particularly formidable type of no-
3,500 sea miles at economical speed. It will be seen that the modern flotilla eader approximates to the light cruiser ent rate of progress is to be maintained "boat" will soon become a misnomer, and we shall revert to the "torpedo cruiser" thirty years ago, though on a much arger scale. In the destroyer and flotilla leader, as in every other type of fighting raft, each new demand for increased armament, speed and sea endurance involves a corresponding increase in size, and there is practically no limit except in the paying power of the nations concerned. But in every class of fighting ship there comes a stage of development which fulfils all reasonable requirements, and beyond which it is unnecessary to go. In the case of the flotilla leader this stage ppears to have been reached in the maller designs set forth in the table hown. War experience has demonstrated vessels as the British Scott class, which, 1,740 tons, combine in a high degree the essential qualities of a destroyer flagship. It is of interest to learn that a tentative provided for a vessel of 1,800 to 1,900 tons, of 37 knots speed, armed with four -inch rapid-fire guns and eight torpedo

Golf Without a Caddy (Continued from page 473)

in fact works out much more wisely than anticipated; when a few ounces can save upward of 25 tons as above, the ounces re certainly working at some high efficiency Think of the perspiration and utter exhaustion that would overtake one were he compelled to go out and raise 25 tons to the height of 1 foot by hand twice a day. How much of either energy or inclination for golf would a man have after climb about 30 stories in one of our tall buildings twice a day? And this is exactly what caddiless golf has been doing to us without our ever suspecting it

With the little device I have referred o, the simple act of resting the bag down on the ground causes it to develop legs which keep it upright and very stable, and with my eye on the ball and without back, grasping the bag, and the act of lifting it from the ground causes the legs
to disappear and the bag looks like any ordinary "Sunday" bag and is little or no heavier.

Another point that I have found important is the following: We all know that "keep your eye on the ball" is even more necessary after the shot is made than while making it, if you have no caddie. It is then the player's job to watch the ball-certainly no caddie is watching it for him Again, one often loses the lie of the ball in the rough while stooping down to get his sticks, thus causing exasperating delays. I have found that it is certainly of surprising convenience to upright "on their toes," so to speak; and to simply reach back, grasping the bag while watching your ball, and be off on the next stroke toward the drop long before he ball lights. This is of great aid in holding your position on the course and I find often aids a whole foursome to hold its position in play. The unerring location of, and getting right off on the ball is certainly an aid, both directly and indirectly, that can hardly be overestimated. in dimensions and armament. If the re the all-round tactical efficiency of such design prepared at Washington last year such an exertion, or by taking the stairs have the sticks right at hand, standing 